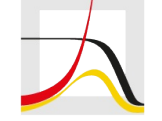

MAX PLANCK INSTITUTE

FOR DEMOGRAPHIC RESEARCH

Konrad-Zuse-Strasse 1 · D-18057 Rostock · Germany · Tel +49 (0) 3812081 - 0 · Fax +49 (0) 3812081 - $202 \cdot$ www.demogr.mpg.de

MPIDR Working Paper WP 2021-003 I February 2021

Revised November 2021

https://doi.org/10.4054/MPIDR-WP-2021-003

\title{
The Demographic Drivers of Grief and Memory after Genocide in Guatemala
}

Diego Alburez-Gutierrez I alburezgutierrez@demogr.mpg.de

This working paper has been approved for release by: Emilio Zagheni (sekzagheni@demogr.mpg.de),

Head of the Laboratory of Digital and Computational Demography.

(c) Copyright is held by the authors.

Working papers of the Max Planck Institute for Demographic Research receive only limited review. Views or opinions expressed in working papers are attributable to the authors and do not necessarily reflect those of the Institute. 


\title{
The Demographic Drivers of Grief and Memory after Genocide in Guatemala 1
}

\author{
Diego Alburez-Gutierrez, PhD \\ Lab of Digital and Computational Demography, \\ Max Planck Institute for Demographic Research, Germany
}

November 18, 2021

\begin{abstract}
Mortality crises are relatively common demographic events, but we know little about how they affect local populations beyond excess mortality. I argue that using a kinship perspective to study mortality crises provides valuable insights into (1) how excess mortality affects the exposure to kin loss, and (2) how family bereavement may contribute to the reproduction of historical memory in the long term. Here, I explore these two processes using a unique genealogical database that records the complete demographic history of Rio Negro, a genocide-affected population in Guatemala, between 1982 and 2015. The analysis shows that deaths from the 1982 genocide were balanced by age, sex, and socio-economic status. One-third of the population were killed, but two-thirds of the population were left bereaved (the top 10\% most affected individuals lost $30 \%$ of their nuclear family relatives and $23 \%$ of their extended family relatives). Notably, the proportion of the population related to a victim did not change between 1983 and 2015. The persistence of family bereavement can be interpreted as a prolongation of grief or as a driver of historical memory. These demographic dynamics have implications for the study of historical events beyond mortality crises.
\end{abstract}

Keywords excess mortality, armed conflict, kinship, demographic change, memory

\section{Introduction}

Mortality crises increase the number of deaths in a population, but the question of to what degree this excess mortality affects an individual's exposure to death in the short and in the long term has not been fully explored. Studies of excess mortality often estimate population-level deaths tolls (Spreeuwenberg, Kroneman, and Paget 2018), the distribution of mortality over demographic characteristics (Walque 2005), or the effects of mortality change on summary statistics (Aburto et al. 2021). While excess mortality is a useful metric of the severity of a crisis, it reflects only the short-term mortality consequences of the crisis. We know little about how excess mortality reverberates within populations and across time.

${ }^{1}$ Please cite as: Alburez-Gutierrez, D. (accepted). "The demographic drivers of grief and memory after genocide in Guatemala." Demography. Temporary DOI:

https://dx.doi.org/10.4054/MPIDR-WP-2021-003. 
Differential exposure to death, especially within the family, has been recognised as a fundamental form of inequality (Umberson et al. 2017) with the potential to shape individual's later-life outcomes (Patterson, Verdery, and Daw 2020). Mortality crises can provide unique insights into how excess mortality shapes the lived experience of death (i.e., the fact that individuals experience mortality primarily as loss). This is also the case for mass killings, which have long been a staple of armed conflicts ${ }^{2}$. As well as having a high death toll, massacres can disrupt the social dynamics that bind social groups together (Card 2003), expose individuals to high levels of gender-based violence (Rehn and Johnson Sirleaf 2002), and deprive survivors of crucial support from family members (Valentino, Huth, and Balch-Lindsay 2004).

Our understanding of the lived experience of mortality crises has been limited by a dearth of longitudinal data on disaster-affected populations, and by a systematic focus on death tolls. These limitations have prevented scholars from properly considering the role of kinship - i.e., the processes that shape human relatedness - as a key mediating force between population-level mortality change and individual-level exposure to death. To study kin loss in the context of excess mortality, data on individuals and their entire family networks over a long period of time would be needed. These data are unlikely to be available for populations in the Global South, where these crises are concentrated.

In this paper, I explore this phenomenon using a unique database containing the complete genealogical information of a Guatemalan village affected by genocide in 1982, during the country's civil war. The objective of this paper is to explore the Janus-like properties of kinship in the context of mortality crises, which can act both as a multiplier of grief and as a vehicle for historical memory. First, I describe the relationship between excess mortality and the experience of kin loss for survivors of the 1982 Rio Negro massacres. Second, I consider how the prevalence of family bereavement, a form of 'demographic memory' (Denton and Spencer 2021), may contribute to the reproduction of historical memory. Overall, the paper shows how pre-existing demographic and kinship structures amplify mortality shocks, and how traces of these events linger over time.

I make three main contributions to the demographic literature. First, I provide empirical evidence on the relationship between mortality change and the lived experience of kin death, which is an important but rarely studied problem. For this purpose, I leverage a novel dataset with an unparalleled level of detail about longitudinal demographic and kinship structures in a genocide-affected population. Second, I highlight the potential of kinship dynamics to reproduce historical memory by multiplying the number of individuals related to the witnesses of an event. This builds on the existing notion that a population's ability to recollect a past event is proportional to the share of individuals in the population who witnessed the event. While Denton and Spencer (2021) have shown how mortality, fertility, and migration affect the development of this 'witness population' in stable

2 Following the convention of the Guatemalan Truth Commission, I define massacres, or mass killings, as violent events resulting in the intentional death of at least five noncombatants (CEH 1999). 
populations, no previous study has used empirical data to analyse the demographic determinants of historical memory after a mortality crisis. Third, I provide the first systematic account of the 1982 Rio Negro massacres, which played a key role in the making of contemporary Guatemala. The Rio Negro massacres are amongst the more than 600 mass killings overseen by the Guatemalan government during the country's civil war. Violent events like those described in this paper accounted for almost half of the estimated 200,000 conflict-related deaths in the country (CEH 1999).

In the next section, I discuss the relevant literature and introduce the genealogical data from Rio Negro, explaining how they were collected and analysed. In the Results section, I examine the implications of excess mortality for the lived experience of kin loss, as well as the demographic drivers of historical memory in Rio Negro. In the final section, I discuss the implications of the findings, focusing on the potential of kinship to multiply grief, and to contribute to the inter-generational transmission of memory.

\section{Background}

Since the end of the Second World War, mass killings have mainly affected relatively small, socially marginalised, and economically deprived communities (Valentino, Huth, and BalchLindsay 2004). These mortality crises affect the social relationships in local communities, disrupting the dynamics of cooperation and support that characterise all human societies. The study of the demographic consequences of mass killings has so far been limited by the lack of high-quality empirical data (Li and Wen 2005). Studies that use aggregate data, often at the country level, are not able to distinguish between deaths from massacres and deaths from other conflict events (Lacina and Gleditsch 2005). While national-level surveys are the most common sources of data used in the demography of armed conflict, they are not well-suited for studying mass killings.

Massacres have specific characteristics that distinguish them from the broader conflicts they are embedded in. They are generally directed towards local communities and affect non-combatants, and they often include extreme psychological and sexual violence (Rehn and Johnson Sirleaf 2002). Studies of the distribution of country-level mortality have shown that younger men (aged 15-44 years) are, on average, more likely to die during conflicts than other groups (Obermeyer, Murray, and Gakidou 2008). It is unclear whether this is also the case for mass killings (Valentino, Huth, and Balch-Lindsay 2004). In the rest of this section, I review how the study of mass killings can provide crucial insights into how populations react to sudden and dramatic changes in mortality.

\section{Excess Mortality and the Lived Experience of Kin Death}

Measures of excess mortality do not capture the full extent to which individuals are affected by mortality crises. Crucially, the survivors of a mortality crisis experience excess mortality as a loss, a phenomenon I refer to as the 'lived experience of death.' Previous studies have shown that exposure to death, especially within the family, is an important form of inequality (Umberson et al. 2017) associated with a range of negative outcomes in later life (Patterson, Verdery, and Daw 2020; Fletcher et al. 2013; Doku et al. 2020). The 
visibility of studies of the lived experience of death over the life-course (Alburez-Gutierrez, Kolk, and Zagheni 2021) and the prevalence of bereavement in a population has increased in recent years (Smith-Greenaway and Weitzman 2020; Smith-Greenaway et al. 2021). These studies have mostly focused on national populations outside of the context of mortality crises. Studying bereavement after mortality crises can provide valuable new insights on the relationship between mortality shocks and the lived experience of kin death for survivors.

Up to now, the relationship between excess mortality and kin loss has only been studied using microsimulation and modelling approaches. A study using demographic microsimulation has, for example, documented the detrimental effect of the HIV/AIDS epidemic on the kinship resources for orphans in Zimbabwe (Zagheni 2011). Theoretical work in demography has described the expected relationship between mortality change and the lived experience of kin death (Keyfitz and Caswell 2005). The empirical study of kinship in the context of mortality crises can improve our understanding of how a demographic memory of these events lingers on in real-world populations.

\section{Demographic Drivers of Memory After an Event}

In this paper, I use the term 'demographic memory' to describe the potential of demographic change to influence the long-term reproduction of historical memory in a population (Denton and Spencer 2021). I focus on two processes: witness survival and family bereavement. Demographic memory should not be confused with other forms of population memory, such as the scars left by mortality crises on population pyramids (Walque 2006). It is also distinct from historical memory, understood as the way in which preserving the memory of an event becomes part of habitual practices within local cultural frameworks (García 2014).

The concept of demographic memory was first used to describe the way in which demographic dynamics determine the proportion of a population who remember a historical event. Consider a population who experienced an important event in the past: What share of the population can be classified as witnesses of this event years after it took place? Denton and Spencer (2021) have shown how, in a stable population framework, the evolution of the population of 'rememberers' is affected by changes in the three pillars of demographic change: mortality, fertility, and migration. The underlying assumption is that a population's ability to recollect a past event is proportional to the share of individuals in the population who witnessed the event. This understanding of demographic memory is closely linked to the theory of 'demographic metabolism' introduced by Ryder (1985) and expounded by Lutz (2013), which studies social change through the lens of cohort replacement.

Witness availability is not the only way in which demographic dynamics help reproduce historical memory. Kinship structures can also play an important role. A recent study estimated that each death from the COVID-19 pandemic in the United States was experienced, on average, by nine grieving relatives (Verdery et al. 2020). In contexts characterised by widespread mortality, it seems reasonable to expect that a considerable proportion of the population will experience the death of a family member. Studies have 
found evidence of the inter-generational transmission of trauma within populations (Cerdeña, Rivera, and Spak 2021), including for very distant events (Aassve et al. 2021). Having a personal connection to the crisis can also contribute to preserving the memory of an event, even amongst individuals who were not directly exposed to it. Life-course theory has long postulated that individuals are embedded in family systems that can be characterised as networks of 'linked lives' (Alwin 2012; Elder 1998, 1994). In the present study, I consider family bereavement to be one such link between living individuals and their deceased relatives. Using empirical data to study the multiplicative effect of kinship after a mortality event can improve our understanding of the potential of family bereavement to act as an inter-generational repository of memory.

\section{The Rio Negro Massacres}

The end of the 1970s was a turbulent period in Central America. In Guatemala, where a civil war against communist guerrillas had been waged since 1960, the military government implemented a series of scorched earth policies targeting the country's indigenous populations. This campaign of mass violence resulted in up to 75,000 casualties over the course of 600 massacres that took place between 1980 and 1982 (CEH 1999; Valentino, Huth, and Balch-Lindsay 2004). A United Nations backed Truth Commission reported that the Guatemalan state committed acts of genocide against the Maya-Achi people between 1981 and 1983 (CEH 1999).

This study analyses the effects of mass violence in Rio Negro, a Maya-Achi village in the heart of the Guatemala Highlands. At the time of the Maya-Achi genocide, Rio Negro was an isolated and impoverished agricultural community. Roughly one-third of the population of Rio Negro perished in a series of massacres targeting unarmed men, women, and children between February and September 1982. These massacres happened after members of the community refused to be resettled during the construction of the Chixoy Hydroelectric Project, the largest and most important hydroelectric power plant in Guatemala (Einbinder 2017). Testimonial evidence suggests that many women over age 10 and some men experienced sexual violence and rape over the course of these events (EAFG 1995; CEH 1999). During a 2008 trial, perpetrators of the Río Negro massacres acknowledged that they had been instructed to kill every person in the village. Most of the houses in Rio Negro were burned down, and the villagers' livestock and crops were plundered or destroyed.

After the killings and up until 1996, when the Guatemalan Civil War ended, the survivors of the Rio Negro massacres were held in a military-controlled facility called Pacux, which operated as a concentration camp with limited access to food and sanitation (EAFG 1995). Extrajudicial killings, torture, and sexual violence were common in the camp, and mobility was highly restricted, which minimised in- and out-migration. Although the massacres of Rio Negro are amongst the most emblematic of all of the state-sponsored acts of violence during the Guatemalan Civil War, they are also amongst the least studied (Einbinder 2017). 


\section{Data and methods}

\section{Primary Data From a Genocide-affected Population}

The primary data used in this analysis come from a unique database containing demographic and genealogical information on all members of a community affected by genocidal massacres and their descendants. The data were reconstructed from genealogical interviews that I carried out with survivors of the 1982 Maya-Achi genocide in Rio Negro, Guatemala, between January and October 2016. All interviews were conducted in the vernacular Maya-Achi language with the help of a team of two local researchers with expert knowledge of the community. All in all, we carried out 112 genealogical interviews in the municipality of Rabinal, where most of the genocide survivors reside, and in other parts of the country (100 were conducted successfully, eight were refused, and four could not be conducted for practical reasons).

The data collection process was designed to improve data reliability while minimising survival and retrospective biases. The genealogical reconstruction relied on multiple genealogical reporting to assess data completion and quality, and to reduce the survival bias that characterises retrospective data collection. This technique, introduced in AlburezGutierrez (2019), aims to collect as many independent reports on the same genealogical person as possible (e.g., the same person can be reported as a sister in an interview and a mother in another interview). The data overlap resulting from the network sampling methodology was used to improve the data quality (on average, a genealogical interview yielded information on 58 individuals, $61 \%$ of whom were duplicates reported in a separate interview). Inconsistencies in the data were discussed with the research team, and, when possible, clarified with the respondents in follow-up interviews. The remaining inconsistencies were resolved using an algorithm based on a series of operationalised assumptions about response patterns: data accuracy decreases with social distance; mothers provide more reliable data about their children than fathers; etc.

We processed the data during the data collection period. This process included transcription, record linkage, and the de-duplication of records. These tasks were performed in parallel by members of the research team to ensure data quality. Each new family tree was merged to the other existing trees until a complete genealogy emerged; i.e., a single family tree with one component and no duplicates. Processing the data in the field allowed me to assess the degree of genealogical saturation in the data, which was the main criterion used to limit the number of interviews with survivors. For a complete description of the data, including details on the data collection, sources of bias, and reliability assessments, see Alburez-Gutierrez (2019).

\section{Secondary Data From Two Local Censuses}

Secondary data for this study came from two unpublished local censuses containing information on the inhabitants of Rio Negro before and after the mass killings. The 1981 census was a de facto census conducted by the Instituto Nacional de Electrificación (INDE), the government's energy company, between 1978 and 1981. It was intended to provide baseline data to guide compensation programmes related to the construction of the Chixoy 
Hydroelectric Project (which were never implemented). The unpublished census report is 500 pages long, and describes the demography, economy, social structure, settlement patterns, and many other aspects of Rio Negro and nearby communities. Crucially, it includes a list with the names and ages of 602 inhabitants of Rio Negro grouped by household. These census data are not entirely reliable, as the political violence in the area had already started when the data were collected. However, they are the only existing data from the time. An analysis of the reported ages showed that they were largely rounded (Whipple's index $=241)^{3}$.

The 2008 census was conducted to identify the beneficiaries of a separate government programme of war reparations that was ongoing when I collected the genealogical data. The census was commissioned by an umbrella organisation for Human Rights, COCAHICH, and was implemented by the Latin American Social Sciences Institute (FLACSO). It was a de jure census, meaning that it registered individuals independent of their current location as long as they were descendants of the original population (i.e., those who were alive at the time of the massacres). This census includes full names, places of birth and dates of birth, and household memberships for 1,303 individuals. The individuals were required to present their national identity card upon registration, which improved the quality of the data. An analysis of the 2008 census data suggested that there was a much lower degree of age-rounding in these data than in the 1981 census data (Whipple's Index $=111$ ). There was a small degree of underreporting, as some members of the population refused to be included in the census. A small number of emigrants (mainly children born from sexual abuse, who were adopted by families abroad) were omitted from the census. Because registration in the census defined their eligibility for war reparations, the inhabitants of Rio Negro (and their descendants) had a strong incentive to participate in the census.

\section{Quality and Completeness of the Genealogical Data}

The Rio Negro genealogy contains data on 3,566 unique individuals, 1,986 marriages, and relational fields linking individuals to their parents and spouses. It represents the entire population of the village between 1960 and 2015, and can be used to reconstruct its kinship structure.

I assessed the completeness of the genealogical data by comparing them with data from the two local censuses described above. I found that $98 \%$ of the individuals recorded in the 1981 and 2008 censuses were also included in the genealogical data (matched by name and date of birth). I also compared the genealogical data to a list of victims who were exhumed in Rio Negro by the Guatemalan Forensic Anthropology Foundation, and identified using DNA matching (FAFG 2018), 90\% of whom were reported independently in the

3 The Whipple index is a standard tool for evaluating the prevalence of age-heaping; values under 105 are considered very accurate, and values over are considered 175 fairly inaccurate. 
genealogical interviews ${ }^{4}$. An analysis of the reported dates of birth in the genealogical data showed little evidence of age-heaping (Whipple's index $=104$ ), and there was no evidence of male bias due to the underreporting of female records, which is a common issue that affects genealogical records (Zhao 2001). Finally, the age-sex distribution of the Rio Negro population was not significantly different from the distribution reported in the 1981 census or in the 2008 census (Alburez-Gutierrez 2019).

The genealogical data are prone to survival bias, as individuals with no living descendants may be less likely to be reported. Nonetheless, the genealogical data approached completeness of death registration even within family groups who suffered very high mortality during the killings. According to the genealogical data, $16 \%$ of the 1981 households had all of their members killed in the massacres, but $97 \%$ of these households were included in the genealogical data (even if they had no living descendants at the time of the data collection).

A final concern was that the data quality for victims of the genocide would be poorer. I conducted a missing value analysis to determine whether genocide victims had more missing values than non-genocide victims in the data. Missing values arose when a given piece of information (e.g., a date or place of birth) could not be reconstructed from the existing genealogical or census data. The analysis showed that after merging the data to create a complete genealogical dataset, the share of missing values was equivalent for victims $(14 \%)$ and survivors (13\%) of the killings. Further underreporting may have resulted if emigrants (i.e., internally displaced persons) were systematically omitted from the dataset. However, outmigration from Pacux (the resettlement camp) was heavily restricted by the Guatemalan army after the massacres, and significant steps were taken during the data collection to include information on emigrants by conducting off-site genealogical interviews. A thorough analysis of retrospective and survivor bias in the genealogical data has been conducted elsewhere (Alburez-Gutierrez 2019).

\section{Analysis}

This paper is based on a descriptive demographic analysis of the complete genealogy of Rio Negro. For every individual, I identified relatives in the nuclear family (parents, siblings, spouses, and children) and the extended family (including members of the nuclear family plus grandparents, grandchildren, cousins, aunts, and uncles). Following Alburez-Gutierrez (2019), I estimated denominators by reconstructing the age and sex composition of the population in any given year from the genealogical records. I identified direct excess deaths using a variable in the genealogical data that recorded whether a given death was conflictrelated or not.

I used data from the 1981 census to establish pre-killings household membership. Using pattern matching techniques, I matched $87 \%$ of the 1981 genealogical population to a census household, while the remaining $13 \%$ could not be matched unequivocally to a

4 The FAFG data include other victims of the Maya-Achi genocide who were buried alongside those of the Rio Negro massacres. 
unique household. This census also included data on the crops, livestock, and land owned by each household, as well as on whether any household member took part in other commercial activities. I used these data to construct a household-level pre-killings socioeconomic index.

\section{Results}

I start by describing the main demographic characteristics of Rio Negro and the excess mortality from the 1982 mass killings. I then discuss the relationship between excess deaths and the experience of kin loss for survivors. Finally, I consider the demographic drivers of historical memory in the 1983-2015 period.

\section{Descriptive Evidence of Excess Mortality in Rio Negro}

In 1981, the year before the killings, Rio Negro was a typical rural Mayan community in Guatemala in terms of its demographic composition and dynamics. It was a kin-centred community, and individuals had high shares of long-lasting and close ties to relatives in their nuclear and extended families. The kinship system in the village was patrilineal, residence was patrilocal, and traditional gender norms prevailed.

The population was young (59\% of the members were under 15 old), homogeneous (all members were indigenous Maya), and relatively isolated (95\% of the members had been born in the village). The population was very impoverished, and the vast majority of the villagers were relying on subsistence agriculture, according to the 1981 census. An analysis of data on crop and livestock ownership in the village prior to the killings shows that there were no wide socio-economic inequalities. Infant mortality rates were very high (89 deaths per 1,000 births) and the prevalence of malnutrition (69\% of children under age 15 were stunted) and of infectious diseases was also high. These values are comparable to those reported for similar contemporaneous Mayan villages (Early 1982). According to the genealogical data, the Total Fertility Rate (TFR) in 1981 Rio Negro, was 7.8, which was above the reported national level for that year (5.9), but was similar to the TFR for the Mayan population in the country as a whole (7.4) (APROFAM 1978). The crude growth rate averaged 0.057 in the 10 years before the killings, and 0.043 in the 10 years after the killings, corresponding to doubling times of 12 and 16 years, respectively. As a result of these trends, the population of Rio Negro increased from 970 inhabitants in 1981 to almost 3,000 in 2016.

The population of Rio Negro shrank by one-third in 1982 (from 970 to 604 inhabitants) as a result of the killings, and did not surpass its pre-genocide size until 1992, 10 years after the massacre. Table 1 shows the distribution of genocide deaths by age and sex according to the genealogical data. Direct mortality from the mass killings was surprisingly balanced by sex: $37 \%$ of all women and $38 \%$ of all men were killed. Mortality was also consistently high across all age groups. While older adults had the highest mortality rates (almost $60 \%$ of individuals aged 45 or older were killed), given the very young structure of the population, more children were killed in total. The extremely high mortality of children stands out: one-third of all children under age 15 died in the massacres. The genocide had 
the side effect of 'rejuvenating' the population - 64\% of survivors were younger than age 15 the year after the killings, compared to $59 \%$ the year before the killings.

Table 1. Age-sex structure of the Rio Negro population before the 1982 killings and excess deaths from the killings. (A) Population by age and sex at the start of 1982; (B) direct deaths from the killings; (C) proportion of the pre-genocide population killed.

\begin{tabular}{|c|c|c|c|c|c|c|c|c|c|c|}
\hline \multirow[t]{2}{*}{ Cohort } & \multirow[t]{2}{*}{$\begin{array}{c}\text { Age in } \\
1982\end{array}$} & \multicolumn{3}{|c|}{$\begin{array}{c}\text { Alive in } 1982 \\
\text { (A) }\end{array}$} & \multicolumn{3}{|c|}{$\begin{array}{l}\text { Killed (total) } \\
\text { (B) }\end{array}$} & \multicolumn{3}{|c|}{$\begin{array}{l}\text { Proportion killed } \\
\qquad(\mathrm{C})=\mathrm{B} / \mathrm{A}\end{array}$} \\
\hline & & All & Female & Male & All & Female & Male & All & Female & Male \\
\hline $\begin{array}{l}1968- \\
1982\end{array}$ & 0 to 14 & 544 & 273 & 271 & 163 & 82 & 81 & .3 & .3 & .3 \\
\hline $\begin{array}{l}1937- \\
1967\end{array}$ & 15 to 44 & 332 & 170 & 162 & 147 & 75 & 72 & .44 & .44 & .44 \\
\hline Pre-1937 & $45+$ & 94 & 43 & 51 & 56 & 22 & 34 & .59 & .51 & .67 \\
\hline All cohorts & All ages & 970 & 486 & 484 & 366 & 179 & 187 & .38 & .37 & .39 \\
\hline
\end{tabular}

The age-sex distribution of excess mortality from the Rio Negro massacres differed considerably from that of the Guatemalan Civil War as a whole, which I estimated using two independent datasets of Human Rights violations ${ }^{5}$. Country-level deaths were, on average, concentrated amongst fighting-age men (aged 20 to 45), but the violence in Rio Negro was directed against the population as a whole. Female mortality was 1.4 times higher in Rio Negro than in the Guatemalan conflict as a whole, and was 1.9 times higher than in other contemporaneous conflicts (Obermeyer, Murray, and Gakidou 2008). Remarkably, excess mortality among under-five children was 6.2 times higher in Rio Negro than in the overall country-level conflict. Moreover, survivors of the killings were, on average, exposed to higher levels of physical, sexual, and psychological violence than other victims of the conflict (CEH 1999; EAFG 1995).

The survivors of the Rio Negro massacres endured many hardships between 1983 and 2015 , especially in the five years after the genocide, when they hid in nearby forests, foraging for food to avoid being captured by the military. This period saw the highest postgenocide mortality rates, especially for children under five. Overall, $40 \%$ of the deaths reported in the 1983-2016 period were of children under 15 and about a third of the deaths were violent (conflict-related at first and gang-related later on). Within a couple of

5 The CIIDH and REHMI are the most comprehensive datasets of retrospective Human Rights violation reports from the Guatemalan Civil War. Both sources relied on independent convenience samples of primary human right violations reports. Age and sex were known only for 35\% of the CIIDH records and 58\% of the REMHI records. 
years of the killings, most survivors had been resettled in Pacux, a blend of a refugee camp and a political prisoner detention center. Migration was heavily restricted by the military, so that few people were allowed to move in or out of the camp. Total Fertility Rates plummeted from 7.8 in 1981 to 2.9 in 1982, before recovering again in a drop-and-rebound pattern (Heuveline and Poch 2007). Fertility remained high up until the year 2000, when it started declining and reached 2.3 in 2016, below the average for the Mayan population (3.6) and for Guatemalans as a whole (3.1).

\section{Effects of Excess Mortality on the Lived Experience of Kin Loss}

Measuring excess mortality is only one way of quantifying the effects of mortality crises. Studies that focus exclusively on casualties disregard the reality that each death implies the loss of parents, siblings, spouses, etc. This omission is partly due to the fact that data on kin loss are seldom available from traditional data sources, such as household surveys.

Table 2. Number of relatives lost by sex and age of genocide survivors at the time of the killings (mean and standard deviation).

\begin{tabular}{|l|l|l|l|l|l|l|}
\hline & \multicolumn{3}{|c|}{ Female survivors } & \multicolumn{3}{c|}{ Male survivors } \\
\hline & \multicolumn{1}{|c|}{$0-14$} & \multicolumn{1}{|c|}{$15-44$} & \multicolumn{1}{|c|}{$45+$} & $0-14$ & $15-44$ & \multicolumn{1}{c|}{$45+$} \\
\hline Nuclear (any) & $1.2(1.7)$ & $2.9(3.2)$ & $3.5(3.1)$ & $1.4(1.7)$ & $2.9(2.8)$ & $3.2(3.3)$ \\
\hline Children & $0(.1)$ & $.5(1.2)$ & $1.8(1.6)$ & $0(.1)$ & $.7(1.3)$ & $1.8(2.1)$ \\
\hline Parents & $.8(.7)$ & $.8(.8)$ & $.6(.8)$ & $.8(.7)$ & $.9(.7)$ & $.4(.7)$ \\
\hline Siblings & $.6(1.3)$ & $1.7(2.5)$ & $1(1.3)$ & $.8(1.3)$ & $1.4(1.7)$ & $.9(2.1)$ \\
\hline Spouses & $0(.1)$ & $.2(.4)$ & $.5(.5)$ & $0(0)$ & $.2(.4)$ & $.3(.5)$ \\
\hline $\begin{array}{l}\text { Extended } \\
\text { (any) }\end{array}$ & $3.8(5.4)$ & $4.9(5.3)$ & $6.1(5.4)$ & $4.5(5.5)$ & $4.6(5.1)$ & $5.8(6.3)$ \\
\hline Grandchildren & $0(0)$ & $.3(.8)$ & $2.6(3.8)$ & $0(0)$ & $.2(.8)$ & $2.7(3.7)$ \\
\hline Grandparents & $.7(1)$ & $.3(.7)$ & $0(0)$ & $.8(1)$ & $.2(.5)$ & $0(0)$ \\
\hline Cousins & $2(3.9)$ & $1.4(3.5)$ & $0(0)$ & $2.3(4)$ & $1.3(3.6)$ & $0(0)$ \\
\hline
\end{tabular}

Table 2 shows the number of relatives lost by survivors of the Maya-Achi genocide by age and sex of the surviving population ( $\mathrm{N}=640)$. Survivors lost, on average, 1.8 members of their nuclear family $(\mathrm{SD}=2.4$ ) and 4.4 members of their extended family $(\mathrm{SD}=5.4)$. The top $10 \%$ most affected individuals (measured by the total number of relatives killed) lost, on average, 4.3 relatives in their nuclear family $(S D=0.5)$ and 10 relatives in their extended family ( $\mathrm{SD}=1.8$ ). These figures represented $30 \%$ and $23 \%$ of the size of their entire nuclear and extended family networks, respectively. In contrast, the $10 \%$ least affected individuals lost no relative in the nuclear family and just 0.7 members of the extended family, representing $2 \%$ of their extended family networks. On average, older individuals lost 
more relatives than younger individuals - the median age of the $10 \%$ most affected individuals was 17, whereas the median age of the $10 \%$ least affected individuals was just 8 (considering only survivors who lost at least one relative). There were no large differences between sexes ( $47 \%$ of the most affected survivors were women, compared to $51 \%$ of the least affected survivors). Note that while the standard deviation increases over age, the coefficient of variation, a measure of relative variability, remains relatively constant (not shown). This is the case for all relative types except for children, grandchildren, and spouses, for whom the coefficient of variation is considerably higher in the youngest age group.

Excess deaths were clustered within family groups. Table 3 shows the proportion of genocide survivors who experienced the death of $n$ or more relatives, conditional on their having experienced the death of $(n-1)$ relatives. For example, $38 \%$ of the genocide survivors experienced the death of at least one sibling, and of these bereaved individuals, $71 \%$ also experienced the death of a second sibling. Note that this is different from the proportion of survivors who lost a given number of siblings because the denominator changes for each column. In the sibling example, the denominator for column $(0 \rightarrow 1+)$ are the 604 survivors who had a living sibling in 1982 (not shown in table), whereas the denominator for column $(1 \rightarrow 2+)$ are the 228 survivors who lost one or more siblings (in square brackets). The key takeaway of this table is that survivors were more likely to lose a second relative conditional on already having lost one relative $(1 \rightarrow 2+)$ than to lose a first relative altogether $(0 \rightarrow 1+)$. This is also the case for higher orders of kin death for all relative types, except for parents.

Table 3. Proportion of genocide survivors who experienced the death of $n$ or more relatives $(n+)$, conditional on having experienced the death of at least $(n-1)$ relatives. In square brackets, population who experienced at least $n$ deaths of a given relative type (i.e., the denominator for each cell).

\begin{tabular}{|l|l|l|l|l|l|}
\hline$(n-1) \rightarrow n+$ & $0 \rightarrow 1+$ & $1 \rightarrow 2+$ & $2 \rightarrow 3+$ & $3 \rightarrow 4+$ & $4 \rightarrow 5+$ \\
\hline Nuclear (Any) & $.59[354]$ & $.68[239]$ & $.79[188]$ & $.63[119]$ & $.72[86]$ \\
\hline Children & $.11[68]$ & $.6[41]$ & $.49[20]$ & $.35[7]$ & $.71[5]$ \\
\hline Parents & $.42[250]$ & $.28[71]$ & & & \\
\hline Siblings & $.38[228]$ & $.71[162]$ & $.67[108]$ & $.47[51]$ & $.49[25]$ \\
\hline Spouses & $.07[44]$ & & & & \\
\hline Extended (Any) & $.66[397]$ & $.86[342]$ & $.91[312]$ & $.83[259]$ & $.84[217]$ \\
\hline Grandchildren & $.08[45]$ & $.69[31]$ & $.65[20]$ & $.65[13]$ & $.69[9]$ \\
\hline Grandparents & $.28[170]$ & $.62[105]$ & $.3[32]$ & $.03[1]$ & \\
\hline Cousins & $.29[173]$ & $.91[158]$ & $.78[124]$ & $.76[94]$ & $.98[92]$ \\
\hline
\end{tabular}


The estimates for grandparents and cousins in Tables 2-3 should be interpreted carefully because data limitations made it impossible to identify some kin ties for the oldest members of the population. For example, to identify the cousin of someone born in 1940, we would need data on their grandparents born in the $19^{\text {th }}$ century, which were not collected. Therefore, kin loss for cousins is likely to be greatly underestimated, particularly for the $45+$ age group (this is also the case for aunts, uncles, nieces, and nephews, who are not included in the table).

\section{Demographic Drivers of Memory After the 1982 Mass Killings}

In this section, I discuss the potential of demographic change to act as a repository of memory. First, I study the survival of genocide witnesses over time under the assumption that survivors are crucial vehicles of historical memory. Second, I consider how kinship dynamics have the potential to keep the memory of the genocide alive in the long term. I regard these two processes as instances of demographic memory, which act as drivers of historical memory.

\section{Witness Survival as a Form of Demographic Memory}

I start by considering the development of the population of genocide witnesses in Rio Negro. Following Denton and Spencer (2021), I define 'witnesses' as individuals who were aged 12 or older in 1982, under the assumption that younger children were too young to remember the events (using alternative awareness ages changes the levels, but not the general trends presented below). This definition does not require that a witness experienced kin loss; although, as shown above, the overwhelming majority of witnesses did lose at least one relative.
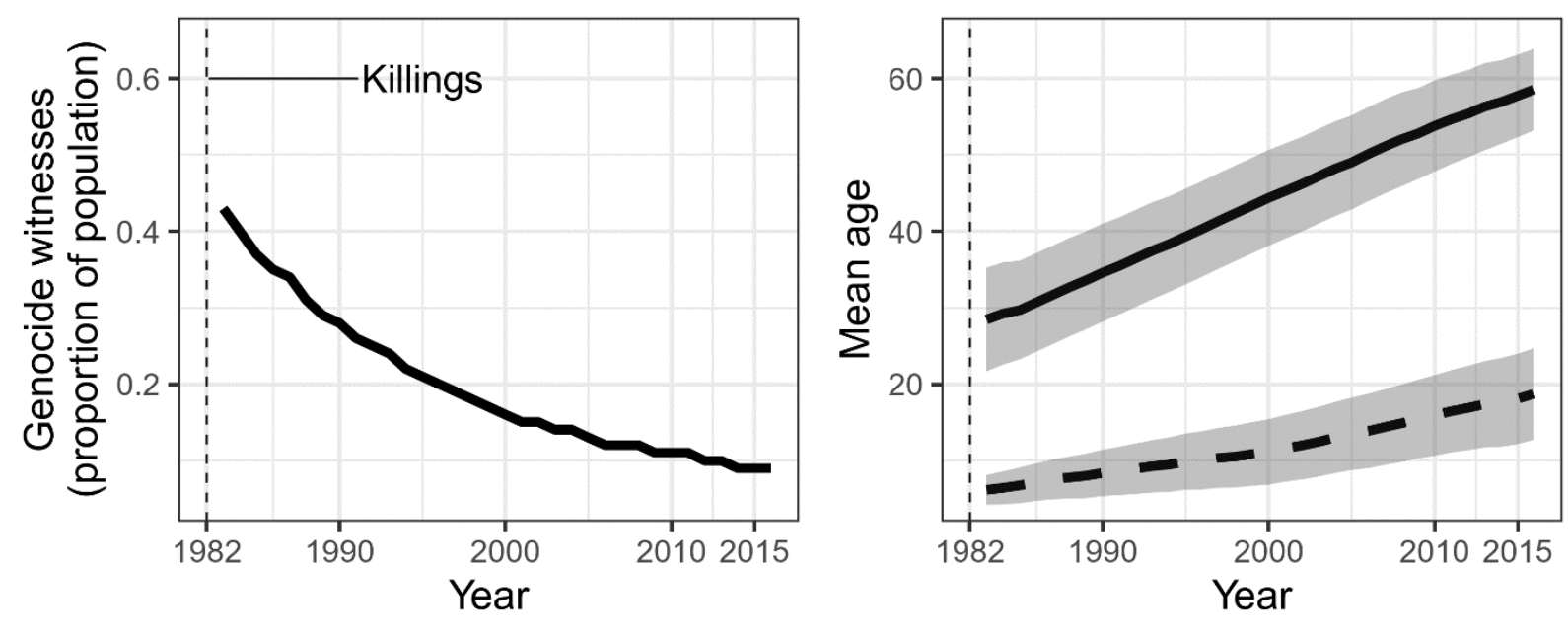

Experience of genocide - - - Non-witness Witness

Fig 1. Historical development of the population of genocide witnesses (survivors who were aged 12 or older in 1982) in Rio Negro (1983-2015 period). Left: Proportion of the total 
population who are witnesses. Right: Mean age of witnesses and of non-witnesses (including 95\% confidence intervals).

The population of Rio Negro witnesses has declined considerably over the years (Figure 1). Assuming a minimum awareness age of 12, almost half of the 1983 population could be considered witnesses. However, this share of the population was only $10 \%$ by 2015 , and will continue to decline in the coming years as no new members can enter the population of witnesses. 'Non-rememberers' made up $91 \%$ of the 2015 population, and will dominate the population in the near future. Genocide witnesses have also aged considerably in the intervening years. On average, witnesses went from being 29 to 58 years old between 1983 and 2015. This increase in age was not fully linear over time given the higher mortality at older ages. In contrast, the population of non-rememberers are very young; i.e., 18 years old on average in 2015.

Finally, I used standard Leslie matrices (Keyfitz and Caswell 2005) to project the population of witnesses and non-rememberers in Rio Negro, assuming exposure to the empirical and projected demographic rates from the 2019 Revision of the United Nations World Population Prospects (medium scenario for the 2015-2050 period). I estimate that by 2025 , less than $5 \%$ of the population will have witnessed the killings. By 2050 , the handful of survivors left will, on average, be aged 85 or older; and thus will, in all likelihood, be unable to give first-hand testimony of the genocide. Witness availability can be regarded as a form of demographic memory but as I show below, it is not the only demographic driver of historical memory.

\section{Prevalence of Bereaved Individuals as a Repository of Memory}

Like all mortality crises, the mass killings in Rio Negro produced a large population of bereaved individuals. In this section, I consider the members of the population related to a victim of the genocide over time. 'Bereavement' refers either to the loss of a family member once known to the person or to the absence of a family member: a 'hole' in the family network. These two complementary definitions of bereavement are explained graphically in Figure 2. Unlike period mortality rates, measures of the prevalence of bereavement reflect the mortality history of the population, and are ideal for quantifying the long-lasting consequences of excess mortality. 


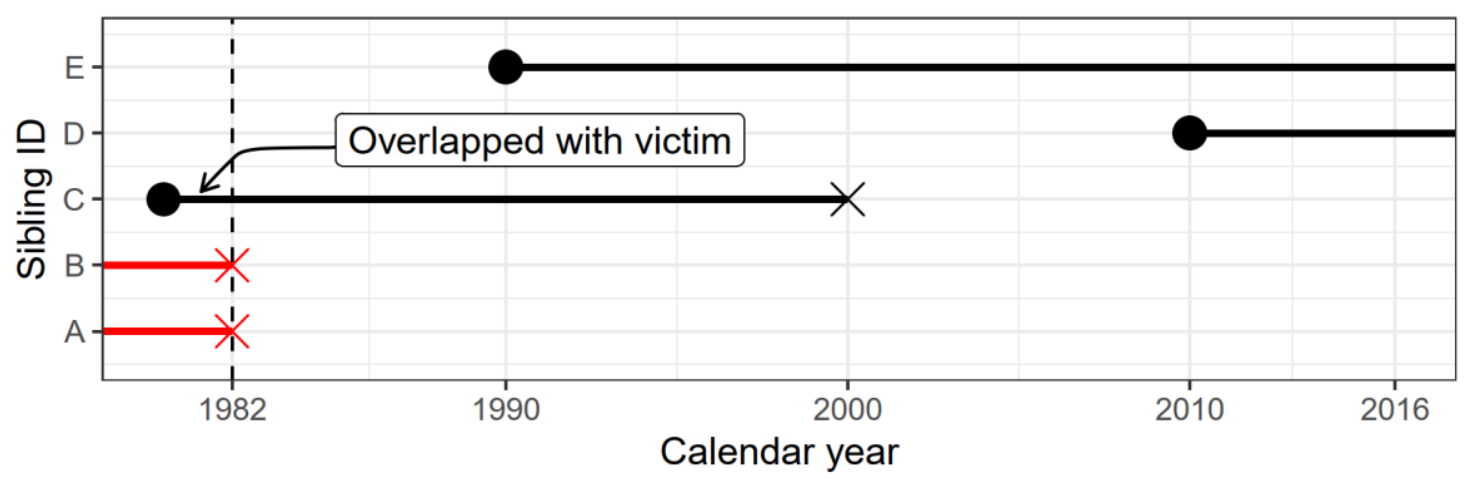

Figure 2. The diagram shows five siblings, two of whom (A-B) died in the 1982 killings (shown by the dashed vertical line). All the surviving siblings ( $\mathrm{C}-\mathrm{E}$ ) are related to a genocide victim (i.e., they are 'bereaved'), but only the life-line of C overlapped with that of a victim.

I start by considering changes in the prevalence of bereavement in Rio Negro. In 1983, 59\% of genocide survivors had lost at least one member of their nuclear family in the genocide, and $66 \%$ had lost a relative in their extended family. Overall, $42 \%$ of survivors lost a parent, $28 \%$ lost a grandparent, and $11 \%$ lost a child. Moreover, $38 \%$ of survivors lost at least one sibling, and 7\% lost a spouse. The top panels of Figure 3 exemplify the differential development of bereavement in the nuclear family and the extended family over time. The proportion of the population with a victim in their nuclear family declined by threequarters between 1983 and 2015 (from 59\% to 19\%). In contrast, the prevalence of bereavement in the extended family fluctuated around $65 \%$ in the same period; meaning that an average member of the 2015 population was almost as likely to be related to a victim of the killings as a member of the 1983 population.

The demographic theory of kinship helps us understand the persistently high levels of bereavement in the extended family. A person cannot acquire new children, older siblings, parents, grandparents, or spouses after death, but she may acquire younger siblings, cousins, nephews, aunts, uncles, or grandchildren. Caswell (2019) has characterised these as processes of 'demographic subsidy.' With the exception of younger siblings, all of these are members of the extended family, which is why indirect bereavement rates for the extended family remained relatively constant after 1983, but declined for the nuclear family.

However, the proportion of the population who knew a victim personally declined over time, even as the prevalence of bereavement remained relatively constant. The bottom panels of Figure 3 show that $63 \%$ of the 1983 population 'overlapped' with at least one genocide victim, compared to just $14 \%$ of the 2015 population. Equivalent declines from higher to lower values along the vertical axis indicate a progressive distancing of individuals and victims for all relative types.

The overlap between individuals and victims over time is a product of demographic change. Assuming population growth, the share of the population who overlapped with a victim must decrease over time, like a cohort effect (i.e., only people born before 1982 are 
'at risk' of having overlapped with a genocide victim). This decline is evident in the bottom panels of Figure 3. The pace of the decline depends on changes in the rate's numerator (the number of people who overlapped with a victim) and denominator (total population). A large influx of non-bereaved individuals into the population (e.g., given sustained population growth or immigration flows) would cause the denominator to increase rapidly. Alternatively, the numerator can also fall rapidly if, for example, survivors who lost a relative also faced above-average mortality risks after the genocide.

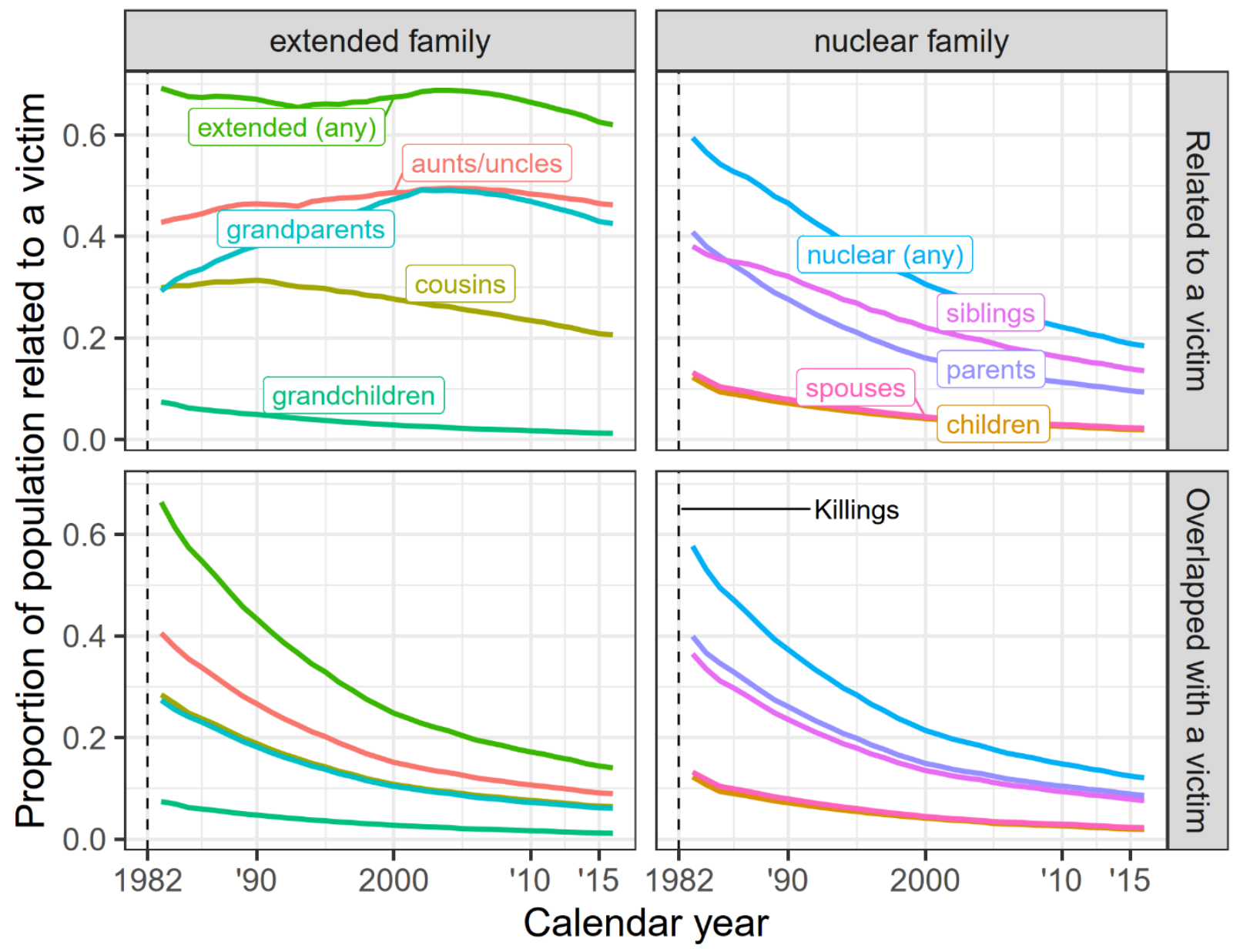

Figure 3. Prevalence of bereavement in Rio Negro by type of relative lost (1983-2016 period). The top panels show the proportion of the population that is related to a victim, regardless of whether individuals actually met the victim or not. The bottom two panels show the proportion of the living population that overlapped with a victim.

Figure 4 shows the population of bereaved individuals by age, sex, and relatedness to a genocide victim at two points in time. The share of the population related to a victim is equivalent in both pyramids, around $65 \%$, but the nature of the relationship between 
individuals and victims is different. Whereas in 1983, the overwhelming majority of the population had overlapped with the victim in their family (red tiles), by 2016, most of the bereaved individuals had actually never met their relative killed in the genocide (green tiles). Nevertheless, three decades after the violence, a substantive segment of the population continued to have a personal connection to the genocide.

\section{Discussion}

This study provided a systematic description of the demographic consequences of mass violence for an indigenous population in Guatemala. I examined the question of how demographic and kinship dynamics shaped the experience of genocide for survivors, while focusing on kin loss and historical memory. The findings highlighted the potential of kinship to elucidate the short- and long-term consequences of excess mortality for members of the local populations who, ultimately, experience these mortality events. In doing so, the study went beyond traditional analyses of excess mortality to highlight the wide-ranging and long-lasting implications of mortality crises for populations. A particular strength of the study was its use of complete genealogies from a population who experienced very high levels of excess mortality, and who were, until recent years, closed to migration.

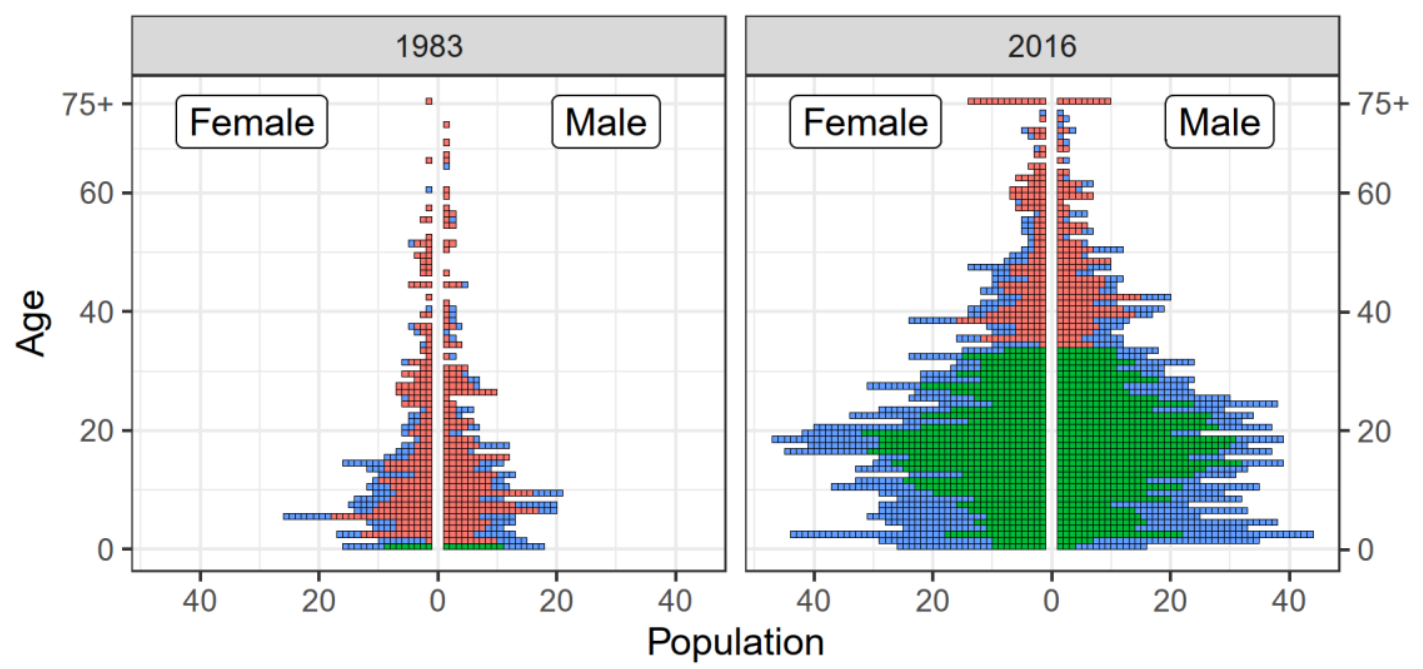

Related to a victim? $\square$ Yes, and overlapped $\square$ Yes, but never overlapped $\square$ No

Figure 4. Population pyramids of Rio Negro in the aftermath of the genocide (left) and 33 years after the violence (right). Individuals (i.e., tiles) are coloured according to their relatedness to a genocide victim (considering any relative in the nuclear or extended family). An individual is said to have 'overlapped' with a victim if the individual was alive when the victim was killed. 
A first set of results highlighted the potential of kinship structures to exacerbate the exposure to death in the context of a mortality crisis. One in three members of the population of Rio Negro were massacred in 1982. Direct excess mortality was evenly distributed by age, sex, and socio-economic status, and there were high levels of clustering within family groups. These excess deaths radically increased the exposure of survivors to kin death. In the aftermath of the killings, two-thirds of survivors had lost at least one member of their extended family. The mortality crisis effectively created a large population of bereaved individuals. The size and the composition of this population were determined by the levels and the distribution of excess deaths on the one hand, and the pre-existing population and kinship structures on the other. Furthermore, the massacres disrupted family networks considerably, making them less connected and reducing opportunities for intra-family cooperation.

A second set of results outlined the demographic determinants of historical memory - i.e., demographic memory - by focusing on the availability of genocide witnesses and the prevalence of bereavement in the population over time. Genocide witnesses in Rio Negro (individuals who were at least 12 years old at the time of the killings) made up little less than one-tenth of the population in 2015. As members of this population of 'rememberers' were relatively old and frail, I projected that, before long, they would be replaced by the population of 'non-rememberers.' Nevertheless, the multiplicative nature of kinship dynamics might contribute to the reproduction of memory amongst younger generations. Individuals with a personal connection to the events, such as relatives of the victims, can be powerful actors in this process, even if they themselves never experienced the mortality crisis.

Demographic memory, as characterised in this study, highlights how demographic change and kinship dynamics may contribute to the inter-generational transmission of memory. This idea is deeply rooted in the existing demographic and sociological theory. The notion that demographic traits can constitute an 'inventory of experience' is not new (Mannheim 1952) although its application to the study of memory in demography is recent (Denton and Spencer 2021). Demographic memory is closely related to the theory of demographic metabolism introduced by Ryder (1985) and developed by Lutz (2013), which centres on the implications of cohort replacement and population composition for social change. However, demographic metabolism ignores the transmission of traits within families (e.g., from parents to children or between siblings), whereas demographic memory recognises that kinship can augment the prevalence of a trait over time. In this respect, demographic memory - or, more accurately, kinship memory - acts like a 'bereavement multiplier' with a longitudinal dimension (Verdery et al. 2020). The idea that families connect historical events and individual experience, so that 'the misfortune of one member is shared through relationships' (Elder 1998 cited in ) is a core tenet of life-course studies (Alwin 2012; Elder 1994). Indeed, several of the insights gained from the empirical study of Rio Negro were anticipated by the literature on linked lives. These include the relational nature of demographic processes and the centrality of kinship for individuals (e.g., Song and Mare 2019; Patterson, Verdery, and Daw 2020). 
This study used empirical data on the same population before, during, and in the 33 years after a mortality event. As a result, the analysis implicitly accounted for the complexity of real-world dynamics, which are impossible to fully model or simulate. Here, I highlight three processes that would be difficult to capture using formal demographic methods (Goodman, Keyfitz, and Pullum 1974; Caswell 2019; Denton and Spencer 2021) or demographic microsimulations (Zagheni 2011; Verdery et al. 2020). First, real-world deaths and excess deaths tend to be clustered. In Rio Negro, deaths were clustered by age, sex, socio-economic status, household membership, and family type. Model-based approaches, which often lack detailed empirical input data, focus on averages that mask this heterogeneity. Second, mortality crises may affect the subsequent demographic behaviour of survivors in conditional ways. For example, women who lost a child may have higher (or lower) fertility after the event. These effects are largely unpredictable at the individual level, making them difficult to model (Randall 2005). Third, demographic behaviours may be transmitted over generations. The inability to account for this is a known limitation of model- and simulation-based studies (Ruggles 1993), which may be more severe in the aftermath of traumatic events (Aassve et al. 2021; Cerdeña, Rivera, and Spak 2021).

The relationship between mortality change and family bereavement described for Rio Negro is universal (mortality begets bereavement), but its relevance for historical memory depends on contextual factors. First- and second-hand testimonies are likely to be essential in local communities like Rio Negro, where State institutions are unlikely to even acknowledge the existence of a genocide (García 2014). In larger societies, the personal experience of loss is not the only way in which memory is transmitted over generations. For example, beyond extensive mortality, the Covid-19 pandemic has brought about unemployment, relationship strains, and educational losses (to name a few). These factors, alongside things like history books, museums, and public rituals (Collins 2004), will shape how the ongoing crisis is remembered by generations to come. Nevertheless, the prevalence of individuals with a 'hole' in their family network remains an intuitive and powerful example of how the 'hidden potentialities inherent in the generation locations' described by Mannheim (1952) can influence memory in the long term. Here, it is worth emphasising that demographic memory is different from historical memory - paraphrasing Ryder (1985), we might say that bereavement does not cause the act of remembering but it aids it.

The present paper makes an important historical contribution. This is the first systematic study of the direct and indirect consequences of the 1982 Rio Negro massacres, which are amongst the most important events of the Guatemalan Civil War and the least studied. However, while the scale of the 1982 Rio Negro massacres was exceptional, they were not an isolated incident in the Guatemalan Civil War. They followed the same pattern as the more than 600 state-sponsored massacres in which tens of thousands of non-combatants were killed (CEH 1999). The findings underline that mass killings are distinctive types of conflict event that should be studied separately from the larger armed conflicts in which they are embedded. Livi-Bacci (2021) has recently warned that war-induced population decline might cause the loss of demographic potential. This applies to Rio Negro, where the population of survivors only surpassed its pre-genocide size 10 years after the violent 
events. Similarly, although the genocide forcibly 'rejuvenated' the population, it also deprived survivors of the human capital needed to take advantage of any 'demographic dividend' associated with a younger age structure (Lutz et al. 2019).

This paper has clear policy implications. Studies on the inter-generational transmission of trauma have shown that even distant events can affect currently living individuals (Cerdeña, Rivera, and Spak 2021) and societies (Aassve et al. 2021). This study underlines the urgency of implementing sustained, long-term interventions to manage trauma after a mortality event. If trauma is indeed inherited over generations, the number of individuals affected by it will necessarily increase steadily over time given population growth and the force of kinship. I focused on a relative measure of the prevalence of trauma: i.e., the proportion of the population related to a victim. Looking at the absolute numbers highlights the magnitude of the problem: the number of individuals related to a victim increased from 440 in 1983 to 1,511 in 2016. Survivors of Rio Negro and of other atrocities are in urgent need of mental health support. The global relevance of this issue has been made evident by the ongoing COVID-19 pandemic, the consequences of which will be felt by bereaved relatives for years, if not generations, to come.

\section{Limitations}

I identify three main limitations in this study. First, the genealogical data were affected by survival and retrospective bias, despite all efforts to minimise them during data collection. Combining the genealogical data with secondary local census data allowed me to estimate the extent of this omission bias ( $2 \%$ of the pre-genocide population), which is unlikely to bias the results considerably. Second, generational depth limited the identification of horizontal kin (e.g., data on grandparents are needed to locate the cousins of an ego), which led to underestimations of family size and kin loss in the extended family for members of older cohorts. Third, the empirical results from this study cannot be generalised to other populations, given that mortality crises differ greatly in their causes and consequences (Randall 2005). Fertility in Rio Negro remained relatively high in the years after 1982, which contributed to the observed stability in the prevalence of bereavement. However, fertility responses to conflict are heterogeneous across contexts (Heuveline and Poch 2007; Nobles, Frankenberg, and Thomas 2015). The degree to which temporary increases in fertility after mortality crises might result in similar trends in other settings is an exciting area for future research.

The idea of a demographic memory is not restricted to the study of armed conflicts. The demographic processes outlined in this paper are generalisable to the degree that an increase in mortality will invariably create a population of bereaved relatives, and the characteristics of this population can be inferred through demographic reasoning. Future studies can apply a demographic memory or kinship memory framework to study other important historical events. Theoretical work, for example, can formalise the relationship between demographic change, the experience of kin loss, and the population-level prevalence of bereavement using tools from mathematical demography. 


\section{Conclusions}

I studied the implications of excess mortality for the experience of kin loss and the persistence of memory over time using complete genealogical data from a genocideaffected population closed to migration. Evidence from the Maya-Achi genocide in Guatemala exemplifies how mortality shocks reverberate within populations, and are amplified by pre-existing demographic and kinship structures. One-third of the population of Rio Negro died in a series of mass killings in 1982, but in the aftermath of the killings over $60 \%$ of all survivors had lost at least one family member in the killings. Remarkably, the proportion of the population related to a victim of the genocide remained relatively constant in the 1983-2015 period. Family bereavement binds cohorts in a shared experience of the past. These findings illustrate the role of kin ties as repositories of memory: i.e., a substantial proportion of the population will continue to have a personal connection to the genocide even after the last direct witness has died. This paper takes advantage of a unique data source containing individual-level data on the same population before, during, and after genocide. The specific findings are unique to the population of Rio Negro, but the mechanisms by which demographic dynamics shape long-term patterns of grief and memory are universal.

\section{Data Availability Statement}

Microdata from this study cannot be shared publicly given privacy concerns. However, a technical description of the data and the scripts used to produce the empirical results of the study are available online: https://www.doi.org/10.17605/OSF.IO/S5TAJ.

\section{Acknowledgments}

I am indebted to the people of Rio Negro and Pacux for sharing their testimonies and to ADIVIMA, COCAHICH, and Gabriela Lajuj for fieldwork support in Guatemala. Maltyox che alaq. The paper was discussed at the Work-in-progress Workshop of the MPIDR Lab of Digital and Computational Demography. I thank Orsola Torrisi, Emanuele Del Fava, Emilio Zagheni, and the four anonymous reviewers for insightful comments. This research was supported by a PhD Studentship (2014-2018) from the London School of Economics and Political Science (Department of Social Policy).

\section{References}

Aassve, Arnstein, Guido Alfani, Francesco Gandolfi, and Marco Le Moglie. 2021. "Epidemics and Trust: The Case of the Spanish Flu." Health Economics, February, 1-18.

https://doi.org/10.1002/hec.4218.

Aburto, Jose Manuel, Ridhi Kashyap, Jonas Schöley, Colin Angus, John Ermisch, Melinda C Mills, and Jennifer Beam Dowd. 2021. "Estimating the Burden of the COVID-19 Pandemic on Mortality, Life Expectancy and Lifespan Inequality in England and Wales: A Population- 
Level Analysis." Journal of Epidemiology and Community Health, January, 1-6. https://doi.org/10.1136/jech-2020-215505.

Alburez-Gutierrez, Diego. 2019. "Blood Is Thicker Than Bloodshed: A Genealogical Approach to Reconstruct Populations After Armed Conflicts." Demographic Research 40 (March): 627-56. https://doi.org/10.4054/DemRes.2019.40.23.

Alburez-Gutierrez, Diego, Martin Kolk, and Emilio Zagheni. 2021. "Women's Experience of Child Death over the Life Course: A Global Demographic Perspective." Demography 58 (5): 1715-35. https://doi.org/10.1215/00703370-9420770.

Alwin, D. F. 2012. "Integrating Varieties of Life Course Concepts." The Journals of Gerontology Series B: Psychological Sciences and Social Sciences 67B (2): 206-20. https://doi.org/10.1093/geronb/gbr146.

APROFAM. 1978. "Encuesta Nacional de Fecundidad, Planificación Familiar Y Comunicación de Guatemala [National Survey of Fertility, Family Planning and Communication in Guatemala]." Guatemala City: Association for Family Welfare of Guatemala.

Card, Claudia. 2003. “Genocide and Social Death." Hypatia 18 (1): 63-79. https://doi.org/10.1111/j.1527-2001.2003.tb00779.x.

Caswell, Hal. 2019. "The Formal Demography of Kinship: A Matrix Formulation." Demographic Research 41 (September): 679-712.

https://doi.org/10.4054/DemRes.2019.41.24.

CEH. 1999. Capítulo Segundo: Las Violaciones de Los Derechos Humanos Y Los Hechos de Violencia [Chapter II: Human Rights Violations and the Acts of Violence]. Guatemala City: UNOPS - Comisión para el Esclarecimiento Histórico.

Cerdeña, Jessica P., Luisa M. Rivera, and Judy M. Spak. 2021. "Intergenerational Trauma in Latinxs: A Scoping Review." Social Science \& Medicine 270 (February): 113662.

https://doi.org/10.1016/j.socscimed.2020.113662.

Collins, Randall. 2004. "Rituals of Solidarity and Security in the Wake of Terrorist Attack." Sociological Theory 22 (1): 53-87. https://doi.org/10.1111/j.1467-9558.2004.00204.x.

Denton, Frank T., and Byron G. Spencer. 2021. "In Living Memory: The Demographic Dynamics of Event Recollection in a Stable Population." Population and Development Review 47 (1): 219-35. https://doi.org/10.1111/padr.12388.

Doku, David Teye, Subas Neupane, Henrik Dobewall, and Arja Rimpelä. 2020. "AlcoholRelated Mortality and All-Cause Mortality Following Bereavement in Two Successive Generations." Edited by Hajo Zeeb. PLOS ONE 15 (12): e0243290.

https://doi.org/10.1371/journal.pone.0243290.

EAFG. 1995. Las Masacres En Rabinal: Estudio Histórico-Antropológico de Las Masacres de Plan de Sánchez, Chichupac Y Río Negro [the Massacres in Rabinal: A Historical- 
Antropological Study of the Massacres in Plan de Sánchez, Chichupac and Río Negro]. Guatemala City: Equipo de Antropología Forense de Guatemala.

Early, John D. 1982. The Demographic Structure and Evolution of a Peasant System: The Guatemalan Population. Boca Raton: University Press of Florida.

Einbinder, Nathan. 2017. Dams, Displacement and Development: Perspectives from Río Negro, Guatemala. SpringerBriefs in Latin American Studies. Cham: Springer International Publishing. https://doi.org/10.1007/978-3-319-51511-3.

Elder, Glen H. 1994. "Time, Human Agency, and Social Change: Perspectives on the Life Course." Social Psychology Quarterly 57 (1): 4-15. https://doi.org/10.2307/2786971.

- - 1 1998. "The Life Course as Developmental Theory." Child Development 69 (1): 1-12. https://doi.org/10.2307/1132065.

FAFG. 2018. "Victims Identified from the Remains Exhumed in Rio Negro." Guatemala City: Fundación de Antropología Forense de Guatemala. https://fafg.org/bd/b_victima.php.

Fletcher, Jason, Marsha Mailick, Jieun Song, and Barbara Wolfe. 2013. "A Sibling Death in the Family: Common and Consequential." Demography 50 (3): 803-26.

https://doi.org/10.1007/s13524-012-0162-4.

García, María Luz. 2014. "The Long Count of Historical Memory: Ixhil Maya Ceremonial Speech in Guatemala: Historical Memory in Ixhil Maya Ceremonial Speech." American Ethnologist 41 (4): 664-80. https://doi.org/10.1111/amet.12104.

Goodman, L. A., N. Keyfitz, and T. W. Pullum. 1974. "Family Formation and the Frequency of Various Kinship Relationships." Theor Popul Biol 5 (1): 1-27.

Heuveline, Patrick., and Bunnak. Poch. 2007. "The Phoenix Population: Demographic Crisis and Rebound in Cambodia." Demography 44 (2): 405-26.

https://doi.org/10.1353/dem.2007.0012.

Keyfitz, Nathan, and Hal Caswell. 2005. Applied Mathematical Demography. New York: Springer.

Lacina, Bethany, and Nils Petter Gleditsch. 2005. "Monitoring Trends in Global Combat: A New Dataset of Battle Deaths." European Journal of Population 21 (2): 145-66. https://doi.org/10.1007/s10680-005-6851-6.

Li, Quan, and Ming Wen. 2005. "The Immediate and Lingering Effects of Armed Conflict on Adult Mortality: A Time-Series Cross-National Analysis." Journal of Peace Research 42 (4): 471-92. https://doi.org/10.1177/0022343305054092.

Livi-Bacci, Massimo. 2021. "Nature, Politics, and the Traumas of Europe." Population and Development Review 47 (3): 579-609. https://doi.org/10.1111/padr.12429. 
Lutz, Wolfgang. 2013. “Demographic Metabolism: A Predictive Theory of Socioeconomic Change." Population and Development Review 38: 283-301.

http://www.jstor.org/stable/23655299.

Lutz, Wolfgang, Jesus Crespo Cuaresma, Endale Kebede, Alexia Prskawetz, Warren C. Sanderson, and Erich Striessnig. 2019. "Education Rather Than Age Structure Brings Demographic Dividend." Proceedings of the National Academy of Sciences 116 (26): 1279812803. https://doi.org/10.1073/pnas.1820362116.

Mannheim, Karl. 1952. “The Problem of Generations.” In Karl Mannheim: Essays, edited by Paul Kecskemeti, 272-322. Routledge.

Nobles, Jenna, Elizabeth Frankenberg, and Duncan Thomas. 2015. "The Effects of Mortality on Fertility: Population Dynamics After a Natural Disaster." Demography 52 (1): 15-38. https://doi.org/10.1007/s13524-014-0362-1.

Obermeyer, Ziad, Christopher J L Murray, and Emmanuela Gakidou. 2008. "Fifty Years of Violent War Deaths from Vietnam to Bosnia: Analysis of Data from the World Health Survey Programme." BMJ 336 (7659): 1482-6. https://doi.org/10.1136/bmj.a137.

Patterson, Sarah E., Ashton M. Verdery, and Jonathan Daw. 2020. "Linked Lives and Childhood Experience of Family Death on Educational Attainment." Socius: Sociological Research for a Dynamic World 6 (January): 1-17. https://doi.org/10.1177/2378023120975594.

Randall, Sara. 2005. "The Demographic Consequences of Conflict, Exile and Repatriation: A Case Study of Malian Tuareg." European Journal of Population 21 (2-3): 291-320.

https://doi.org/10.1007/s10680-005-6857-0.

Rehn, Elisabeth, and Ellen Johnson Sirleaf. 2002. Women, War and Peace: The Independent Experts' Assessment on the Impact of Armed Conflict on Women and Women's Role in PeaceBuilding. New York: United Nations Development Fund for Women.

Ruggles, Steven. 1993. "Confessions of a Microsimulator: Problems in Modeling the Demography of Kinship." Historical Methods: A Journal of Quantitative and Interdisciplinary History 26 (4): 161-69. https://doi.org/10.1080/01615440.1993.9956352.

Ryder, Norman B. 1985. “The Cohort as a Concept in the Study of Social Change.” In Cohort Analysis in Social Research: Beyond the Identification Problem, edited by William M. Mason and Stephen E. Fienberg, 9-44. New York, NY: Springer New York.

https://doi.org/10.1007/978-1-4613-8536-3_2.

Smith-Greenaway, Emily, Diego Alburez-Gutierrez, Jenny Trinitapoli, and Emilio Zagheni. 2021. "Global Burden of Maternal Bereavement: Indicators of the Cumulative Prevalence of Child Loss." BMJ Global Health 6 (4): e004837. https://doi.org/10.1136/bmjgh-2020004837.

Smith-Greenaway, Emily, and Abigail Weitzman. 2020. "Sibling Mortality Burden in LowIncome Countries: A Descriptive Analysis of Sibling Death in Africa, Asia, and Latin America 
and the Caribbean." Edited by Bruno Masquelier. PLOS ONE 15 (10): 1-20.

https://doi.org/10.1371/journal.pone.0236498.

Song, Xi, and Robert D. Mare. 2019. "Shared Lifetimes, Multigenerational Exposure, and Educational Mobility." Demography 56 (3): 891-916. https://doi.org/10.1007/s13524019-00772-8.

Spreeuwenberg, Peter, Madelon Kroneman, and John Paget. 2018. "Reassessing the Global Mortality Burden of the 1918 Influenza Pandemic." American Journal of Epidemiology 187 (12): 2561-7. https://doi.org/10.1093/aje/kwy191.

Umberson, Debra, Julie Skalamera Olson, Robert Crosnoe, Hui Liu, Tetyana Pudrovska, and Rachel Donnelly. 2017. "Death of Family Members as an Overlooked Source of Racial Disadvantage in the United States." Proceedings of the National Academy of Sciences 114 (5): 915-20. https://doi.org/10.1073/pnas.1605599114.

Valentino, Benjamin, Paul Huth, and Dylan Balch-Lindsay. 2004. "'Draining the Sea": Mass Killing and Guerrilla Warfare." International Organization 58 (2): 375-407. http://www.jstor.org/stable/3877862.

Verdery, Ashton M., Emily Smith-Greenaway, Rachel Margolis, and Jonathan Daw. 2020. "Tracking the Reach of COVID-19 Kin Loss with a Bereavement Multiplier Applied to the United States." Proceedings of the National Academy of Sciences 117 (30): 17695-17701. https://doi.org/10.1073/pnas.2007476117.

Walque, Damien. 2005. "Selective Mortality During the Khmer Rouge Period in Cambodia." Population and Development Review 31 (2): 351-68. https://doi.org/10.1111/j.17284457.2005.00069.x.

Walque, Damien de. 2006. "The Socio-Demographic Legacy of the Khmer Rouge Period in Cambodia." Population Studies 60 (2): 223-31.

https://doi.org/10.1080/00324720600684767.

Zagheni, Emilio. 2011. "The Impact of the HIV/AIDS Epidemic on Kinship Resources for Orphans in Zimbabwe." Population and Development Review 37 (4): 761-83. https://doi.org/10.1111/j.1728-4457.2011.00456.x.

Zhao, Zhongwei. 2001. "Chinese Genealogies as a Source for Demographic Research: A Further Assessment of Their Reliability and Biases." Population Studies 55 (2): 181-93. https://doi.org/10.1080/00324720127690. 